\title{
Pengaruh Lama Penundaan Pengecatan Setelah Fiksasi Apusan Darah Tepi Terhadap Morfologi Eritrosit
}

\author{
Nurul Warsita ${ }^{1}$, Zainal Fikri ${ }^{2}$, Pancawati Ariami ${ }^{3}$ \\ ${ }^{1-3}$ Jurusan Analis Kesehatan, Poltekkes Kemenkes Mataram, Indonesia
}

\section{Article Info}

Article history:

Received Apr $10^{\text {th }}, 2019$

Revised Mei $15^{\text {th }}, 2019$

Accepted Jun $27^{\text {th }}, 2019$

\section{Keyword:}

Duration of Delay Erythrocyte Morphology Fixation

\begin{abstract}
Blood smear preparations aim to assess the morphology of erythrocytes, leukocytes and platelets. In previous Giemsa staining blood smear preparations were fixed using methanol absolute. Objective to determine the long-standing effect of postponing staining after fixation of peripheral blood smear on the morphology of erythrocytes. Research Quasi Experimental with sampling techniques using Non Random Purposive Simple. The data obtained were analyzed statistically usingtest analysis Chi-square. Microscopic observations of the color and size of erythrocytes in peripheral blood giemsa staining with a comparison of the length of stall delay for 1, 2, 3, 4 and 5 days had a good criteria morphology. Changes in the form of cataract on erythrocytes occur starting on the second day (20\%) with medium criteria, day $3(60 \%)$ with the criteria being, day 4 (60\%) with the criteria being, day $5(40 \%)$ with moderate criteria and (40\%) with poor criteria.test. Results Chi Square obtained $p$ value of $0.048(<0.05)$ with a confidence level of $95 \%$, indicating that there are significant delays painting long after the fixation of the peripheral blood smear of the morphology of erythrocytes Crenation Conclusion: The effect of long delays painting after fixation in the form of red cell morphology changes forming cramps occurs since the second day of delay.
\end{abstract}

Copyright ( Jurnal Analis Medika Bio Sains All rights reserved.

\begin{abstract}
ABSTRAK
Sediaan apus darah bertujuan untuk menilai morfologi eritrosit, leukosit, dan trombosit. Dalam pengecatan Giemsa sebelumnya sediaan apus darah difiksasi menggunakan methanol absolute. Tujuan untuk Mengetahui adanya pengaruh lama penundaan pengecatan setelah fiksasi apusan darah tepi terhadap morfologi eritrosit. Penelitian Quasi Experimental dengan teknik pengambilan sampel menggunakan Non Random Purposive Simple. Data yang diperoleh dianalisa secara statistik menggunakan analisis uji Chisquare. Hasil: Pengamatan mikroskopis terhadap warna dan ukuran eritrosit dengan lama penundaan pengecatan selama 1, 2, 3, 4 dan 5 hari memiliki morfologi kriteria yang baik. Perubahan bentuk krenasi pada eritrosit terjadi mulai penundaan hari ke 2 (20\%) dengan kriteria sedang, hari ke $3(60 \%)$ dengan kriteria sedang, hari ke 4 (60\%) dengan kriteria sedang, hari ke $5(40 \%)$ dengan kriteria sedang dan (40\%) dengan kriteria buruk. Hasil uji Chi Square didapatkan nilai p sebesar $0,048(<0,05)$ dengan tingkat kepercayaan 95\%, menunjukkan bahwa terdapat pengaruh lama penundaan pengecatan setelah fiksasi apusan darah tepi terhadap morfologi krenasi eritrosit. Kesimpulan: Pengaruh lama penundaan pengecatan setelah fiksasi berupa perubahan morfologi eritrosit yang membentuk krenasi terjadi sejak hari kedua penundaan.
\end{abstract}

Kata Kunci : Fiksasi, Lama Penundaan, Morfologi Eritrosit 


\section{Pendahuluan}

Pemeriksaan laboratorium merupakan salah satu sarana untuk mengetahui serta memonitoring kondisi kesehatan. Salah satu pemeriksaan yang sering dilakukan adalah pemeriksaan hematologi. Pemeriksaan hematologi meliputi pemeriksaan hematologi rutin dan pemeriksaan hematologi khusus. Pemeriksaan hematologi rutin terdiri dari beberapa jenis pemeriksaan, diantaranya pemeriksaan hemoglobin, hitung jumlah eritrosit, jumlah trombosit, jumlah leukosit, hitung jenis leukosit, hematokrit, laju endap darah, retikulosit dan pemeriksaan hemostasis ${ }^{1}$.

Pemeriksaan darah rutin seperti hitung jenis sel darah dapat dimanfaatkan untuk menentukan karakteristik morfologi darah. Hitung jenis ini dilakukan dengan prosedur tertentu yaitu mengoleskan setetes darah vena atau kapiler setelah itu dengan hati-hati ditipiskan diatas objectglass (kaca obyek) kemudian dilakukan pengecatan dengan giemsa / wright. Pemeriksaan ini disebut sediaan apus darah tepi ${ }^{2}$.

Dalam pengecatan giemsa, sebelumnya sediaan apus darah difiksasi menggunakan methanol absolute. Fiksasi harus segera dilakukan setelah sediaan dikering anginkan karena apabila tidak dilakukan fiksasi maka akan memberikan latar belakang biru. Fiksasi menggunakan methanol absolute selama 5 menit berfungsi untuk membuka dinding sel eritrosit. Methanol jika didiamkan terlalu lama dalam udara akan menguap dan mengandung air sehingga akan mempengaruhi morfologi eritrosit. Fiksasi methanol absolute berfungsi agar apusan darah dapat menyerap cat dengan sempurna, juga dapat melekatkan apusan darah pada obyek glass sehingga apusan darah tidak mengelupas serta menghentikan proses metabolisme tanpa mengubah keadaan (struktur) sebenarnya ${ }^{3}$.

Larutan fiksasi yang tidak baik dapat menyebabkan perubahan morfologi sel dan perlekatan yang tidak baik. Ini dapat terjadi apabila larutan fiksasi yang digunakan methanol yang tidak absolute karena telah menguap dan dapat mengubah konsentrasi dari methanol tersebut yang dapat menyebabkan fiksasi yang tidak sempurna ${ }^{4}$.

Lamanya pengecatan setelah fiksasi apusan darah tepi sering dianggap tidak penting oleh beberapa tenaga laboratorium. Dalam kondisi khusus penelitian atau pengambilan sampel di lapangan seperti di daerah-daerah terpencil yang jauh dari akses layanan kesehatan mengharuskan peneliti untuk melakukan penundaan waktu pemeriksaan apusan darah tepi.

Penundaan waktu ini dapat disebabkan dua hal, yaitu keterlambatan pengiriman sampel ke laboratorium serta tertundanya waktu pemeriksaan sampel. Keterlambatan dalam pengiriman sampel dapat disebabkan beberapa faktor contohnya pada proses pengumpulan sampel dalam jumlah yang tidak sedikit sehingga diperlukan waktu berhari-hari untuk mendapatkan hasil yang sesuai. Selain itu jarak tempuh yang jauh dalam proses pengiriman sampel menuju laboratorium juga berkontribusi pada keterlambatan pemeriksaan sampel.

Saat ini, masih banyak dijumpai penundaan pemeriksaan darah yang terjadi di lapangan. Namun durasi waktu maksimum untuk dilakukan pemeriksaan masih bervariasi. Faktor inilah yang melatar belakangi penulis untuk melakukan penelitian tentang pengaruh lama penundaan pengecatan setelah fiksasi apusan darah tepi terhadap morfologi eritrosit.

\section{Metode Penelitian}

Penlitian ini merupakan jenis penelitian Eksperimen Semu (Quasi Experimental Designs), yaitu suatu penelitian dengan melakukan kegiatan percobaan, yang bertujuan untuk mengetahui gejala atau pengaruh yang timbul sebagai dari adanya perlakuan tertentu ${ }^{5}$. Penelitian ini tidak memberikan variasi perlakuan ataupun pengukuran berulang sebelum dan sesudah perlakuan, melainkan hanya memberikan variasi waktu penundaan pengecatan pada masing-masing sampel yang diambil. Pengaruh yang dilihat adalah dengan menguji lama penundaan pengecatan setelah fiksasi apusan darah tepi terhadap morfologi eritrosit. Perlakuan pada penelitian ini sebanyak 5 macam perlakuan, yaitu menggunakan lama waktu penundaan pengecatan setelah fiksasi selama 1 hari, 2 hari, 3 hari, 4 hari dan 5 hari. 
Hasil Penelitian dan Pembahasan

Hasil penelitian lama penundaan pengecatan setelah fiksasi apusan darah tepi terhadap morfologi warna, ukuran dan bentuk eritrosit dapat dilihat pada tabel dibawah ini :

Tabel 4.1 Hasil Pengamatan Morfologi Warna Eritrosit

\begin{tabular}{|c|c|c|c|c|c|c|}
\hline \multirow[b]{2}{*}{ Waktu } & \multicolumn{4}{|c|}{ Warna } & \multirow[b]{2}{*}{ Total } & \multirow[b]{2}{*}{$\%$} \\
\hline & Normokrom & $\%$ & $\begin{array}{l}\text { Hipokrom/ } \\
\text { Hiperkrom }\end{array}$ & $\%$ & & \\
\hline 1 Hari & 5 & 100 & 0 & 0,0 & 5 & 100 \\
\hline 2 Hari & 5 & 100 & 0 & 0,0 & 5 & 100 \\
\hline 3 Hari & 5 & 100 & 0 & 0,0 & 5 & 100 \\
\hline 4 Hari & 5 & 100 & 0 & 0,0 & 5 & 100 \\
\hline 5 Hari & 5 & 100 & 0 & 0,0 & 5 & 100 \\
\hline Jumlah & 25 & 100 & 0 & 0,0 & 25 & 100 \\
\hline
\end{tabular}

Tabel 4.1. Hasil pengamatan morfologi warna eritrosit terhadap lima sampel menunjukkan hasil bahwa preparat apusan darah dengan penundaan pengecatan setelah fiksasi selama 1 hari, 2 hari, 3 hari, 4 hari dan 5 hari menunjukkan hasil yang sama, yaitu lima sampel (100\%) memiliki kriteria morfologi yang baik. Artinya bahwa tidak terdapat perubahan warna pada eritrosit. Gambaran morfologi warna eritrosit secara mikroskopis memiliki karakteristik yaitu eritrosit tampak berwarna merah dan dibagian tengahnya tampak lebih pucat yang diameternya kira-kira sepertiga dari keseluruhan diameter eritrosit. Hal ini menunjukkan bahwa semua sediaan apusan darah tepi masih dalam kondisi baik Variasi warna menunjukkan kandungan sitoplasma yang dapat disebabkan kurangnya besi atau menggambarkan ketidak matangan sel.

Tabel 4.2. Hasil Pengamatan Morfologi Ukuran Eritrosit

\begin{tabular}{ccccccc}
\hline \multirow{2}{*}{ Waktu } & \multicolumn{5}{c}{ Ukuran } & \\
\cline { 2 - 6 } & Normositik & $\%$ & $\begin{array}{l}\text { Mikrositik/ } \\
\text { Makrositik }\end{array}$ & $\%$ & Total & $\%$ \\
\hline 1 Hari & 5 & 100 & 0 & 0,0 & 5 & 100 \\
\hline 2 Hari & 5 & 100 & 0 & 0,0 & 5 & 100 \\
\hline 3 Hari & 5 & 100 & 0 & 0,0 & 5 & 100 \\
\hline 4 Hari & 5 & 100 & 0 & 0,0 & 5 & 100 \\
\hline 5 Hari & 5 & 100 & 0 & 0,0 & 5 & 100 \\
\hline Jumlah & 25 & 100 & 0 & 0,0 & 25 & 100 \\
\hline
\end{tabular}

Tabel 4.2. Hasil pengamatan morfologi ukuran eritrosit terhadap lima sampel menunjukkan hasil bahwa preparat apusan darah dengan penundaan pengecatan setelah fiksasi selama 1 hari, 2 hari, 3 hari, 4 hari dan 5 hari menunjukkan hasil yang sama, yaitu lima preparat (100\%) memiliki kriteria morfologi yang baik. Artinya bahwa tidak terdapat perubahan ukuran pada eritrosit. Gambaran morfologi warna eritrosit secara mikroskopis memiliki karakteristik yaitu eritrosit tampak bulat dan memiliki diameter / ukuran dengan variasi yang sama dengan eritrosit normal yaitu berdiameter $6 \mu \mathrm{m}-8 \mu \mathrm{m}$ dan berukuran 8 × 8 x $1-2 \mu \mathrm{m}$ dengan volume $80 \mu \mathrm{m}^{3}$. Hal ini menunjukkan bahwa semua sediaan apusan darah tepi masih dalam kondisi baik. Perubahan ukuran eritrosit dapat disebabkan oleh terganggunya proses mitosis, sintesis hemoglobin, kelainan organel sel dan lainnya ${ }^{6}$.

Tabel 4.3. Hasil Pengamatan Morfologi Bentuk Krenasi Eritrosit

\begin{tabular}{ccccccccc}
\hline \multirow{2}{*}{ Waktu } & \multicolumn{7}{c}{ Bentuk Krenasi } & \\
\cline { 2 - 7 } & \multirow{2}{*}{ Baik } & $\%$ & Sedang & $\%$ & Buruk & $\%$ & Total & $\%$ \\
\hline 1 Hari & 5 & 100 & 0 & 0,0 & 0 & 0,0 & 5 & 100 \\
\hline 2 Hari & 4 & 80,0 & 1 & 20,0 & 0 & 0,0 & 5 & 100 \\
\hline 3 Hari & 2 & 40,0 & 3 & 60,0 & 0 & 0,0 & 5 & 100 \\
\hline 4 Hari & 2 & 40,0 & 3 & 60,0 & 0 & 0,0 & 5 & 100 \\
\hline 5 Hari & 1 & 20,0 & 2 & 40,0 & 2 & 40,0 & 5 & 100 \\
\hline Jumlah & 14 & 56,0 & 9 & 36,0 & 2 & 8,0 & 25 & 100 \\
\hline
\end{tabular}


Tabel 4.3. diperoleh hasil penundaan pengecatan setelah fiksasi selama 1 hari ditemukan 5 preparat (100\%) memiliki mikroskopis bentuk eritrosit yang baik. Penundaan pengecatan selama 2 hari ditemukan 4 preparat $(80,0 \%)$ dengan kriteria baik dan 1 preparat $(20,0 \%)$ dengan kriteria sedang. Penundaan pengecatan selama 3 hari ditemukan 2 preparat $(40,0 \%)$ dengan kriteria baik dan 3 preparat $(60,0 \%)$ dengan kriteria sedang. Penundaan pengecatan selama 4 hari ditemukan 2 preparat $(40,0 \%)$ dengan kriteria baik, 3 preparat $(60,0 \%)$ dengan kriteria sedang. Penundaan pengecatan selama 5 hari ditemukan 1 preparat $(20,0 \%)$ dengan krieria baik, 2 preparat (40,0\%) dengan kriteria sedang dan 2 preparat (40,0\%) dengan kriteria buruk.

Hasil krenasi sediaan apus darah tepi dengan perbandingan lama penundaan pengecatan setelah fiksasi selama 1 hari, 2 hari, 3 hari, 4 hari dan 5 hari dapat dilihat pada gambar di bawah ini

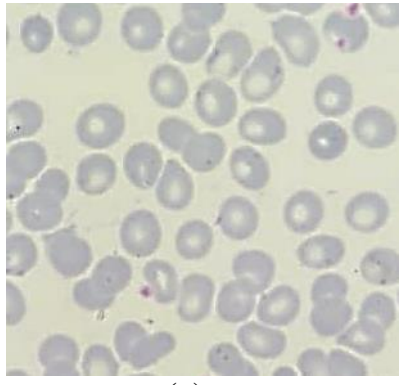

(a)

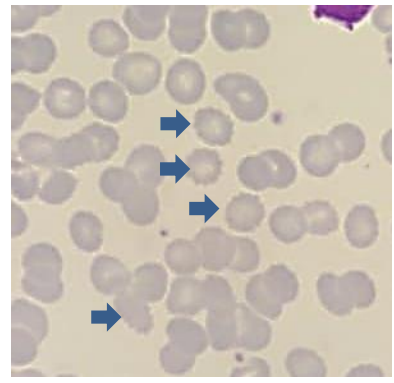

(b)

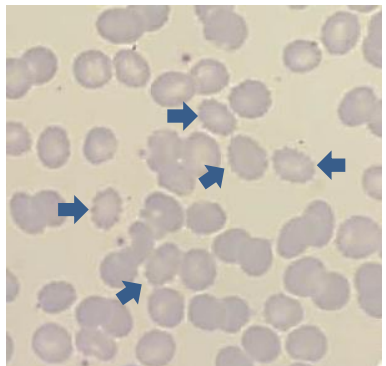

(c)

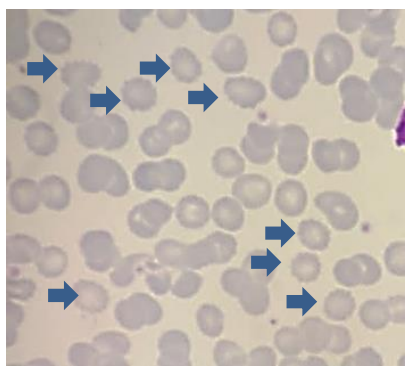

(d)

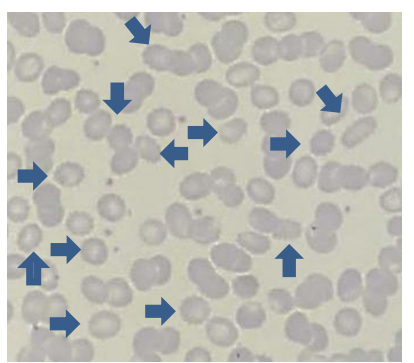

(e)

Gambar 1. (a) krenasi hari 1 (b) krenasi hari 2 (c) krenasi hari 3 (d) krenasi hari 4 (e) krenasi hari 5

Hasil pengamatan mikroskopis terhadap morfologi bentuk krenasi eritrosit ditemukan bahwa lama penundaan pengecatan selama 1 hari tidak memberikan pengaruh terhadap morfologi bentuk eritrosit, artinya semua sediaan apusan darah tepi masih dalam keadaan baik. Sedangkan lama penundaan pengecatan setelah fiksasi selama 2 hari, 3 hari, 4 hari dan 5 hari memberikan pengaruh terhadap morfologi bentuk eritrosit (krenasi). Hal ini terjadi karena sel eritrosit yang telah difiksasi tidak langsung dilakukan pengecatan sehingga hasil krenasi mengalami kecenderungan perubahan menjadi lebih buruk.

Sel Krenasi merupakan kelainan bentuk dari eritrosit (poikilositosis) yang berbentuk seperti artefak. Krenasi berawal dari sel eritrosit yang mengalami pengerutan akibat cairan yang berada di dalam sel keluar melalui membran. Fiksasi yang tidak baik menyebabkan perubahan morfologi dan warna sediaan menjadi tidak baik.

Membran eritrosit bersifat semi permeabel yang berarti dapat ditembus oleh zat air dan zat-zat tertentu yang lain. Apabila eritrosit berada dalam lingkungan yang hipertonis, maka tekanan osmosis akan terjadi dari dalam sel ke luar sel yang akan menyebabkan sel mengalami krenasi (pengerutan), sedangkan apabila eritrosit berada dalam lingkungan yang hipotonis, maka osmosis akan terjadi dari luar ke dalam sel yang akan menyebabkan sel akan menggembung hingga sel burr ${ }^{7}$.

Faktor lain yang dapat mempengaruhi terjadinya bentuk krenasi eritrosit ialah perubahan suhu yang tidak stabil pada saat pengeringan preparat baik sebelum dilakukannya fiksasi maupun setelah dilakukannya fiksasi. Suhu merupakan faktor yang dapat mempengaruhi kuwalitas darah. Darah apabila disimpan pada suhu yang tinggi dapat menyebabkan sel darah merah menjadi rusak, yaitu pecahnya membran sel eritrosit yang disebabkan oleh pemanasan sehingga menyebabkan perubahan pada morfologi eritrosit ${ }^{8}$ 


\section{Kesimpulan}

Pengaruh lama penundaan pengecatan setelah fiksasi berupa perubahan morfologi eritrosit yang membentuk krenasi terjadi sejak hari kedua penundaan. Pengecatan preparat sediaan apus darah tepi sebaiknya dilakukan segera (tanpa adanya penundaan). Jika mengharuskan peneliti untuk melakukan penundaan waktu pemeriksaan karena kondisi khusus penelitian, maka penundaan pengecatan setelah fiksasi harus dilakukan maksimal 1 hari.

\section{Daftar Pustaka}

1. D'Hiru. 2013. Live Blood Analysis. Gramedia Pustaka Utama: Jakarta.

2. FK UNDIP. 2010. Petunjuk Praktikum Patologi Klinik. Penerbit Bursa Buku Senat Mahasiswa FK UNDIP

3. Houwen, Berend. 2000. Blood Film Preparation and Staining Procedures. California. Ioma Linda University School of medicine

4. Masters, S. B. 2002. Farmakologi Dasar dan Klinik katzing: alkohol. Salemba Medika: Jakarta.

5. Notoatmodjo, Soekidjo. 2012. Metodologi Penelitian Kesehatan. Rineka Cipta: Jakarta.

6. Nugraha, Gilang. 2015. Panduan Pemeriksaan Laboratorium Hematologi Dasar. Trans Info Media: Jakarta.

7. Passini, kirkegaard, Mortensen, Lutz, Thomas, Mann. 2006. Blood.

8. Rudyatmi, Ely. 2011. Bahan Ajar Mikroteknik. Jurusan Biologi FMIPA UNNES, Semarang. 